\title{
CODIFICACIÓN Y DECODIFICACIÓN DEL MENSAJE PERIODÍSTICO. UNA EXPERIENCIA DIDÁCTICA
}

\author{
Estrella Martínez-Rodrigo: Universidad de Málaga (España) \\ Pura Raya González: Escuela Superior de Comunicación de Granada (España)
}

\section{Introducción}

Este artículo pretende aplicar la teoría de Stuart Hall 'Encoding and Decoding' (apoyándose también en la semiótica de Charles S. Peirce, Roland Barthes y Umberto Eco) a una propuesta educativa para alumnos de cuarto curso de las licenciaturas de Periodismo y Comunicación Audiovisual. El objetivo es que estos estudiantes no sólo construyan un mensaje textual y audiovisual y a continuación analicen qué mecanismos de codificación se han llevado a cabo en dicho proceso, sino que, en un papel de consumidores, desgranen los elementos de descodificación utilizados durante el tiempo de recepción. Con ello se persigue despertar en el alumnado una actitud crítica y dotarlo de útiles herramientas que le permitan llevar a cabo un consumo más racional y reflexivo de los Medios de comunicación de masas y ejercer su profesión con mayor eficiencia y rigor.

\section{Fundamentación teórica}

Stuart Hall defiende que todos los sistemas de comunicación públicos representan a la ideología dominante y, por tanto, la codificación y decodificación de los mensajes depende de los procesos de connotación y denotación. En el circuito de la comunicación, como defiende el mismo autor, la materia prima se transforma en discurso y antes de producir un efecto, satisfacer una necesidad o darle uso, se dota de sentido y se decodifica su significado para ser percibido como mensaje.

Hall relaciona el análisis del mensaje, sobre todo el televisivo, con la semiótica de Charles S. Peirce, Umberto Eco y Roland Barthes, según la cual, el mensaje lingüístico ayuda a identificar la escena misma. Para ser descifrado, dicho mensaje no requiere más conocimientos que el de la escritura y tiene dos funciones:

- Denominativa: Corresponde a un anclaje de todos los sentidos posibles (denotados) del objeto mediante el empleo de una nomenclatura y ya no guía tanto la identificación como la interpretación.

- De relevo: Establece una relación complementaria con la imagen. ${ }^{1}$

Bebiendo de las teorías de Barthes, Hall también habla de otros dos mensajes: el denotado y el connotado. El primero, constituye un mensaje privativo, constituido por

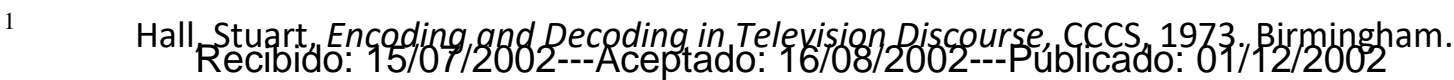


lo que queda en la imagen cuando se borran mentalmente los signos de connotación y dotado de un sentido a nivel de la identificación de la escena representada. El mensaje connotado, tal y como afirma el autor, es el mensaje simbólico o cultural, entendiendo que el número de lecturas de una misma lexía varía según los individuos y su cultura.

En este escenario, Hall distingue dos grandes paradigmas en el análisis semiótico que le llevan a afirmar que la comunicación es tanto un hecho como un discurso:

- La significación entendida como una práctica de la producción de significado (Barthes, Levi-Strauss y Althusser) que analiza la producción pero no la decodificación.

- $\quad$ Entroncar la construcción de los discursos visuales y textuales con los procesos psicoanalíticos primarios, prestando especial atención al sujeto (Lacan, Freud, Althusser).

Sin embargo, entiende que la competencia para decodificar un mensaje que, como el televisivo, implique la lectura de texto e imagen, está distribuida de manera desigual entre productor y receptor, aunque existan relaciones entre ambos. En este sentido, habla de una "mala lectura" del código audiovisual a un nivel denotativo y de "mapas de significado" que provocan "fallos" en el trabajo de decodificación en los que se esconde una cultura. En general, estos "malentendidos", "ruidos" o "malinterpretaciones" que apunta Hall se resuelven a nivel de denotación pero no a nivel connotativo, donde entra en juego la ideología y factores sociales, económicos y políticos.

En ese proceso de decodificación que lleva a cabo la audiencia de los Medios de comunicación de masas, se pueden dar, según Stuart Hall, cuatro "tipos ideales": 2

- Código dominante o hegemónico: el público descodifica el mensaje según la intención del productor. Es lo que se denomina "comunicación transparente".

- $\quad$ Código profesional: el que emplean los profesionales de los medios para transmitir el mensaje del código hegemónico con cierta autonomía.

- Código negociado o posición: mezcla elementos de oposición y adaptación al código dominante.

- $\quad$ Código de oposición: la audiencia entiende el mensaje de un modo totalmente opuesto al dominante y con un esquema conceptual de referencia alternativo.

Hall, Stuart, "Codificar y Decodificar", en Culture, Media y Lenguaje, 1980. Hutchinson (London). Pág. 9. 
En definitiva, y como se ha señalado anteriormente, los errores de denotación no son problemáticos, al contrario que los ruidos o malinterpretaciones connotativas o contextuales, pues suponen un nivel de análisis cimentado en valores culturales y sociales.

Como también señala Hall, la falta de "adecuación" entre los códigos tiene mucho que ver con las diferencias estructurales entre emisor y receptor y con la asimetría entre fuente y audiencia en el momento de la transformación hacia dentro y hacia fuera del "mensaje-forma". La falta de equivalencia entre esos dos polos del intercambio comunicativo es lo que origina precisamente esa "distorsión" del discurso.

Como se puede observar en el siguiente esquema ${ }^{3} \mathrm{y}$, en consonancia con lo expuesto en el párrafo anterior, los códigos de codificación y decodificación del mensaje no tienen por qué ser totalmente simétricos.

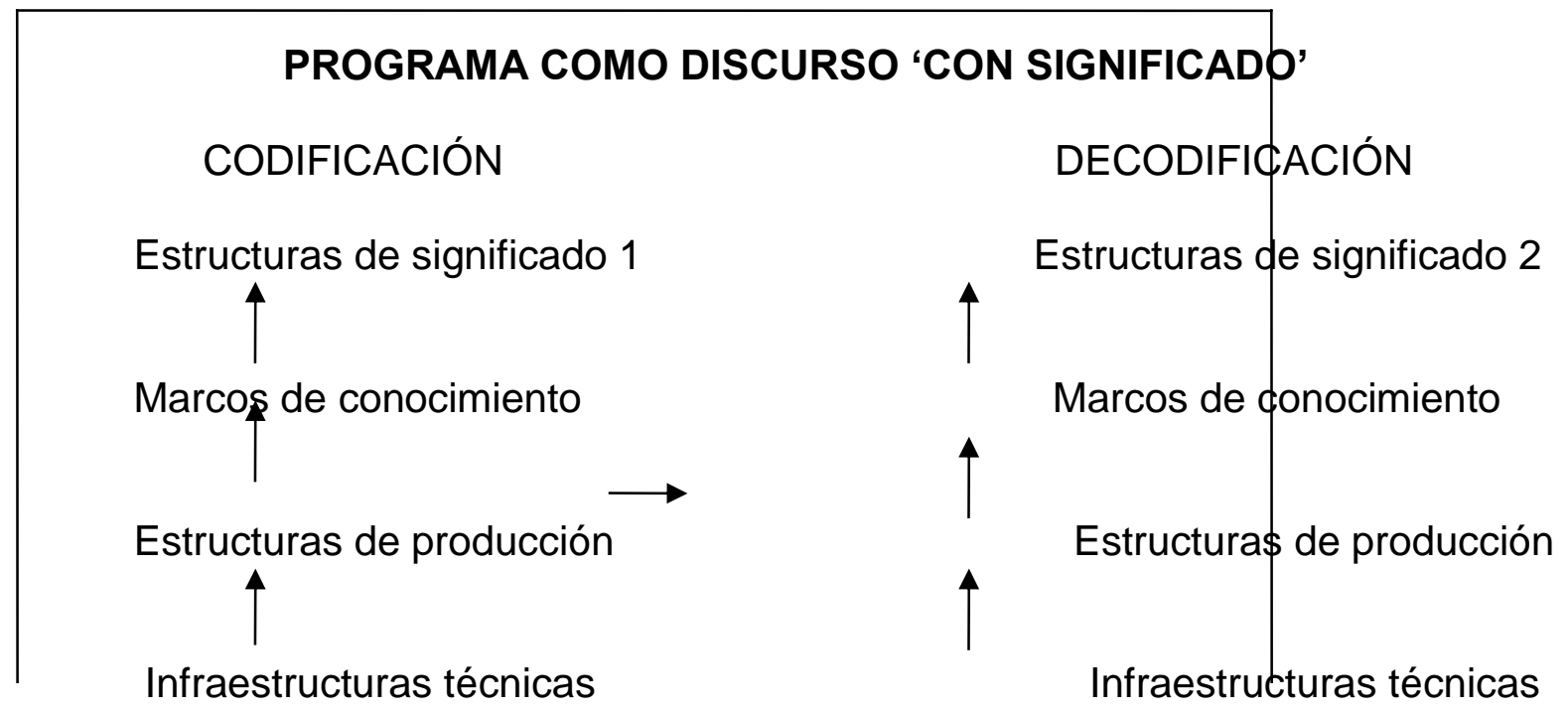

Hall concluye que la producción y recepción del mensaje no son idénticas pero están relacionadas; son momentos diferenciados dentro de la totalidad formada por las relaciones sociales del proceso comunicativo como un todo. Por otra parte, el autor critica el modelo tradicional Emisor - Mensaje - Receptor por su linealidad y plantea un proceso de comunicación basado en las relaciones de los momentos de producción discursiva: Producción - Circulación - Distribución - Consumo Reproducción. Esto quiere decir, que el receptor más que decodificar, recodifica o construye sus propios mensajes a partir de los previamente adquiridos. ${ }^{4}$ 
Otro de los pilares sobre los que se sustenta la propuesta educativa que se explica en el apartado 3 de este artículo, tiene que ver con el análisis del discurso. Para Foucault, un discurso es algo más que un conjunto de enunciados, es una práctica.

Se renunciará, pues, a ver en el discurso un fenómeno de expresión, la traducción verbal de una síntesis efectuada por otra parte; se buscará en él más bien un campo de regularidad para diversas posiciones de subjetividad. El discurso concebido así, no es la manifestación majestuosamente desarrollada de un sujeto que piensa, que conoce y que lo dice. Es, por el contrario, un conjunto donde pueden determinarse la dispersión del sujeto y su discontinuidad consigo mismo. Es un espacio de exterioridad donde se despliega una red de ámbitos distintos. ${ }^{5}$

En este sentido, Foucault añade que todo discurso tiene un contexto de producción que es la "formación discursiva", entendida por él como "un haz complejo de relaciones que funcionan como reglas: prescribe lo que ha de ponerse en relación en una práctica discursiva para que ésta se refiera a tal o cual objeto" ${ }^{6}$ El autor define práctica discursiva como reglas anónimas constituidas en el proceso histórico, es decir, determinadas en el tiempo y delimitadas en el espacio, que se van definiendo, en una época concreta y en grupos o comunidades específicos, las condiciones que hacen posible cualquier enunciación.

Foucault no niega que los discursos están conformados por signos que representan una realidad, pero rechaza que éstos tan sólo se sirvan de los signos para revelar cosas.

Por último, apoyamos esta experiencia didáctica en algunas de las reflexiones que hace Mar de Fontcuberta en su obra "La notica. Pistas para percibir el mundo". Según esta autora, la selección que hace los Medios de Comunicación de sus contenidos se basa en la inclusión y exclusión de información y en la jerarquización de la misma, si bien dicha selección muestra la valoración que cada medio hace de los hechos, buscando que el público tenga opinión y otorgue la importancia a los mismos temas que el medio y con la misma intensidad.

Fontcuberta también recoge una afirmación de Lorenzo Gomis (1987), que dice que aunque los medios se dirigen a un segmento heterogéneo y amplio de personas, cada uno tiene su audiencia. Existe una cierta unidad en él determinada por un cierto grado de cultura común, tradiciones, sentimientos, costumbres... y por los impulsos que recibe a través de los medios de comunicación. Este público tiende a seleccionar la información de acuerdo a sus intereses, cada vez más específicos y exigentes. 7

En esta línea, Carl Warren enumeró ocho elementos que, en mayor o menor proporción, debía contener un hecho para convertirse en noticia: actualidad, proximidad, prominencia, curiosidad, conflicto, suspense, emoción y consecuencias. La gente suele estar interesada por conocer lo que ocurre en un entorno cercano

Foucault, Michel, La arqueología del saber, Ed. Siglo Veintiuno, 1970. México. Pág. 90.

Ibídem. Pág. 122

De Fontcuberta, Mar, La noticia. Pistas para percibir el mundo, Ed. Paidós, 1993. Barcelona. 
(por cercanía debe entenderse no sólo la geográfica sino la social o incluso psicológica), con lo que la proximidad es uno de los factores más poderosos a la hora de elegir una noticia. Quién es el protagonista de la historia, el hecho de que en el mensaje se hable de conflicto y que el tema repercuta en la vida cotidiana del receptor son aspectos que, sin duda, también hacen más noticiable un acontecimiento. $^{8}$

A pesar de que la imagen tiene autonomía narrativa, algunas veces necesita el apoyo del texto y de la voz para adquirir una significación plena. Algunas no necesitan añadido porque son muy simbólicas, pero estos casos son lo menos. Normalmente es necesaria una contextualización para favorecer la comprensión, y evitar equívocos y dobles interpretaciones.

En definitiva, el agente emisor de mensajes periodísticos es un codificador que interviene de manera no intencionada el proceso de la comunicación. ${ }^{9}$

\section{Propuesta didáctica}

Este proyecto educativo está diseñado para llevarse a cabo en entre alumnos de cuarto curso de las licenciaturas de Periodismo y Comunicación Audiovisual. Su principal objetivo es fomentar en los futuros profesionales una actitud crítica y autocrítica que les permita elaborar un mensaje textual y audiovisual efectivo y hacer una lectura de discursos de la misma naturaleza basada en el proceso de decodificación que defiende Stuart Hall y en las estrategias de análisis del discurso de Foucault anteriormente explicadas.

En un primer ejercicio, los estudiantes asumirán dos roles diferentes: 'emisores de un discurso audiovisual' y 'emisores de un discurso textual y fotográfico', y como tales, desempeñarán labores de redacción, toma de imágenes fijas y captación de imagen en movimiento. Todos irán rotando por los distintos puestos. Se hará mucho hincapié en la importancia de trabajar en equipo, tomar decisiones, adquirir responsabilidades y resolver posibles problemas o imprevistos, algo muy común en la profesión periodística.

A un primer grupo, distribuido por equipos de parejas, se le encargará la elaboración de una noticia a partir de la cobertura de una rueda de prensa. Pero habrá equipos que trabajen el tema para su difusión en una televisión de ámbito local y otros que lo hagan para un periódico escrito también de distribución provincial. Igualmente, la mitad hará un tratamiento del asunto pensando en una línea editorial conservadora y el resto con la vista puesta en un medio de comunicación más progresista.

Los integrantes del segundo grupo, con estas mismas consignas, se repartirán las tareas de igual forma que estos compañeros y tendrán una misión idéntica, pero en lugar de cubrir un acto programado y 'de agenda', producirán un reportaje sobre un tema de actualidad propuesto por el profesor o por ellos mismos, para lo que se hará un sondeo al inicio de curso. En este caso, los estudiantes no sólo procederán a la

Grijelmo, Álex, El estilo del periodista, Ed. Taurus, 2001. Madrid.

Martínez Albertos, José Luis, Curso general de redacción periodística, Ed. Thomson, 2002. Madrid. 
grabación de imágenes y a la realización de entrevistas, sino que deberán de preproducir y producir su producto audiovisual documentándose, seleccionando fuentes, localizando escenarios y determinando el estilo que imprimirle al reportaje. Es decir, que hay un trabajo arduo y previo a la salida al exterior en la redacción (aula).

Para las salidas a la calle, que se desarrollarían en cuatro horas de clase, se precisará el siguiente material audiovisual: una cámara profesional, trípode, cinta, micrófono de mano (con pie) y de corbata, baterías, cables, grabadora de voz, libreta, bolígrafo y cámara de fotos con su batería.

La siguiente semana de clase se impartirá en el aula de edición. Los estudiantes 'redactores' procederán a la elaboración y locución del texto, sin perder de visa "el medio para el que le trabajan". De esta manera, harán una determinada selección y desestimación de fuentes y datos, pues el límite temporal de la pieza final de TV será un minuto y medio y la extensión fijada para la prensa escrita será de 3.500 caracteres con espacios, y le darán al discurso una estructura y un estilo muy particular.

Quienes ocupen el cargo de "operador de cámara" también asumirán la labor de montaje del video no lineal (ordenador). También elegirán unos planos y desecharán otros en función de la intencionalidad que quieran darle al mensaje. Los 'fotógrafos' volcarán y retocarán sus imágenes en base a los mismos preceptos.

Una vez dado por concluido el proceso de producción de las noticias, se intercambiarán los trabajos durante otras dos horas de clase. Es decir, los alumnos del grupo 1 serán telespectadores y lectores de los trabajos del grupo 2, y viceversa. Tras un consumo reposado, una semana más tarde, los estudiantes expondrán en alto y por escrito durante una hora qué estrategias de decodificación han seguido durante la recepción del mensaje, es decir, qué lectura han hecho del mismo y qué efectos les ha producido éste. Los sesenta minutos posteriores se destinarán a hacer una valoración común de las diferencias entre las variadas aportaciones del alumnado.

Con la siguiente actividad propuesta se trabajarán los aspectos de codificación del discurso. Para ello, los estudiantes comentarán, también en alto, qué pasos han seguido a la hora de construir o codificar el mensaje, sobre todo teniendo en cuenta que les fue asignada una línea editorial a la que ajustarse, igual que una extensión y temática concretas, en tiempo para TV y espacio en el caso de prensa escrita. Esta valoración se contrastará con la que hagan otros alumnos sobre la construcción del discurso llevada a cabo por estos compañeros Además, los estudiantes rellenarán una ficha, cuyo modelo podría ser el siguiente:

Nombre del alumno/a:

Noticia analizada:

Fuentes consultadas: número, tipología, tiempo o espacio dedicado a ellas en la noticia

Fuentes seleccionadas: número, tipología, tiempo o espacio dedicado a ellas en la noticia 
Localizaciones previstas: número, características

Localizaciones grabadas/pisadas: número, características

Localizaciones utilizadas: número, características

Información recabada:

Información usada en la pieza:

Información desechada:

Priorización de información (orden de datos, titular elegido...)

Duración de la pieza o extensión del texto:

Planos (encuadre, movimientos de cámara...)

Fotografía (prensa escrita): encuadre, posición de la cámara o punto de vista, contenido, retoques...

Edición (música, ambientes, efectos, transiciones, ritmo...)

Tratamiento del tema (personalización, estética, emotividad, contexto...)

Interpretación personal del mensaje

Interés en el tema abordado

Estilo lingüístico del texto (intencionalidad en verbos...)

Efectos del mensaje (finalidad...)

En este sentido, el profesor tratará de que los alumnos descubran que dicho proceso de codificación varía mucho en función de los aspectos expuestos y, cómo no, del medio de difusión utilizado, como se define en el apartado anterior con palabras de Martínez Albertos.

El mensaje televisivo cuenta con mayores recursos de transmisión y provocación que el propio de la prensa escrita, pues se sustenta en audio e imagen. Así pues, requiere un mayor apoyo en lo visual y un lenguaje mucho menos descriptivo cuya finalidad es captar la atención de un espectador que, progresivamente, pierde nivel de atención sobre el discurso y que puede estar compaginando esta actividad con otras.

Por el contrario, el mensaje puramente periodístico se apoya sólo en herramientas lingüísticas, con sustento en la imagen fija (fotografía), y origina una lectura o consumo mucho más reposado, reflexivo y concentrado.

Lógicamente, la percepción del 'receptor' sobre el mensaje que sea y el efecto que éste le produzca van a estar muy marcados en función, entre otras cosas, de sus circunstancias sociales y culturales o de su ideología (análisis el discurso de Foucault). En este sentido, y como señala Stuart Hall, se observará que los objetivos del productor de la noticia y los de la audiencia no coinciden y en ello tiene mucho que ver, como también se dijo en la fundamentación teórica, el valor connotativo del mensaje, donde encuentra cabida el poder de la subjetividad que defiende Roland Barthes.

La evaluación del ejercicio de cada alumno atenderá al nivel de participación e implicación del estudiante, así como a su capacidad de argumentación y de trabajo en equipo, su actitud crítica y autocrítica, su estilo (en cuanto a reacción como a toma de imagen fija o en movimiento, retoque fotográfico y edición de video) y su fidelidad a las pautas marcadas por el profesor (extensión/duración, temática, tratamiento...). 
Además, el docente extraerá unas conclusiones de la experiencia, con el fin de corregir errores y mejorar la actividad de cara a su desarrollo durante cursos posteriores. Para ello, también se valdrá de la opinión de los propios alumnos, a los que se les pasará un cuestionario.

Por último, los trabajos finales se podrían proyectar en pantallas de los pasillos de la facultad para que otros estudiantes hagan su propia lectura discursiva de los mismos.

\section{Referencias}

DE FONTCUBERTA, Mar, La noticia. Pistas para percibir el mundo, Ed. Paidós, Barcelona, 1993.

FOUCAULT, Michel, La arqueología del saber, Ed. Siglo Veintiuno, México, 1970.

GRIJELMO, Álex, El estilo del periodista, Ed. Taurus, Madrid, 2001.

HALL, Stuart, Encoding and Decoding in Television Discourse, CCCS, Birmingham, 1973.

HALL, Stuart, "Codificar y Decodificar", en Culture, Media y Lenguaje, Hutchinson (London), 1980. Págs. 129-139.

MARTÍNEZ ALBERTOS, José Luis, Curso general de redacción periodística, Ed. Thomson, Universidad Complutense de Madrid, 2002. 